E3S Web of Conferences 1, 07008 (2013)

DOI: $10.1051 / \mathrm{e} 3$ sconf/20130107008

(c) Owned by the authors, published by EDP Sciences, 2013

\title{
Assessing Atmospheric Deposition of Mercury in Florida, USA: Local versus Global Sources and Models versus Measurements
}

\author{
S. Sillman ${ }^{1}$, F. Marsik ${ }^{2}$, J. T. Dvonch ${ }^{3}$ and G.J. Keeler ${ }^{4}$ \\ ${ }^{1}$ University of Michigan Air Quality Laboratory, Ann Arbor, MI 48109, USA, sillman@umich.edu \\ ${ }^{2}$ University of Michigan Air Quality Laboratory, Ann Arbor, MI 48109, USA, marsik@umich.edu \\ ${ }^{3}$ University of Michigan Air Quality Laboratory, Ann Arbor, MI 48109, USA, dvonch@umich.edu \\ ${ }^{4}$ University of Michigan Air Quality Laboratory, Ann Arbor, MI 48109, USA, deceased.
}

\begin{abstract}
We compare results from the CMAQ photochemical model for mercury deposition in Florida with measurements from 2009 associated with the Florida Mercury TMDL project, with focus on the question: can model predictions for the impact of local versus global emissions be validated versus measurements? Model wet deposition shows reasonable agreement with measurements, and the lack of variation between sites in Florida in both model and measurements is consistent with the model prediction for limited impact from local sources. Local sources have a larger impact on dry deposition. However, the model overestimates ambient RGM by a factor of 10 versus measured values.
\end{abstract}

Key words: Mercury, photochemical modeling, CMAQ

\section{Introduction}

Wet deposition of mercury ( $\mathrm{Hg})$ in the U.S. is significantly higher in Florida than many locations elsewhere, despite the fact that emissions are higher in the midwestern U.S. Deposition of mercury in Florida is of concern especially because elevated levels of mercury have been found in Florida freshwater lake ecosystems, including fish caught for human consumption. In order to respond to this environmental hazard it is necessary to address the question: to what extent is mercury deposition sensitive to local emissions in Florida as opposed to the global cycle of mercury?

\section{Methods}

Here, we report results from a multiscale photochemistry-transport model used to evaluate the sources of mercury deposition in Florida, in comparison with measurements from the Florida TMDL during the year 2009. The model is the EPA Community Multiscale Air Quality model (CMAQ), including gas and aqueous-phase photochemistry for ozone and related species, chlorine, sulfate, nitrate, mercury and several other trace metals. CMAQ has been used to simulate nested horizontal grids with horizontal resolution ranging from $35 \mathrm{~km}$ for a domain representing the entire US to
$4 \times 4 \mathrm{~km}$ for a domain covering the state of Florida, and with background concentrations supplied by the ECHMERIT global model. A tagging system has been developed that traces model mercury from 14 source categories and is used to identify sensitivity to emissions from sources in Florida and elsewhere, including the global background.

\section{Results and Discussion}

Model results predict that Florida emissions account for a relatively small fraction of mercury wet deposition even at urban locations near emission sources (Figure 1). Local emissions account for $25 \%$ of annual wet deposition at Davie (in the Miami-Fort Lauderdale metropolitan area) and just $12 \%$ during the summer rainy season. This contrasts with the measurement-based analysis by Dvonch et al. (1999) which found that $70 \%$ of wet deposition during summer was attributed to local emission sources. Local emissions have been decreased by at least a factor of three since 1996 when the Dvonch et al. measurements were made. The model predicts that Florida emissions account for a larger fraction of dry deposition (58\% at Davie) and that dry deposition is comparable to wet deposition in magnitude. However, Florida emissions account for a much smaller amount of both wet and dry deposition at rural sites (less than $2 \%$ at 


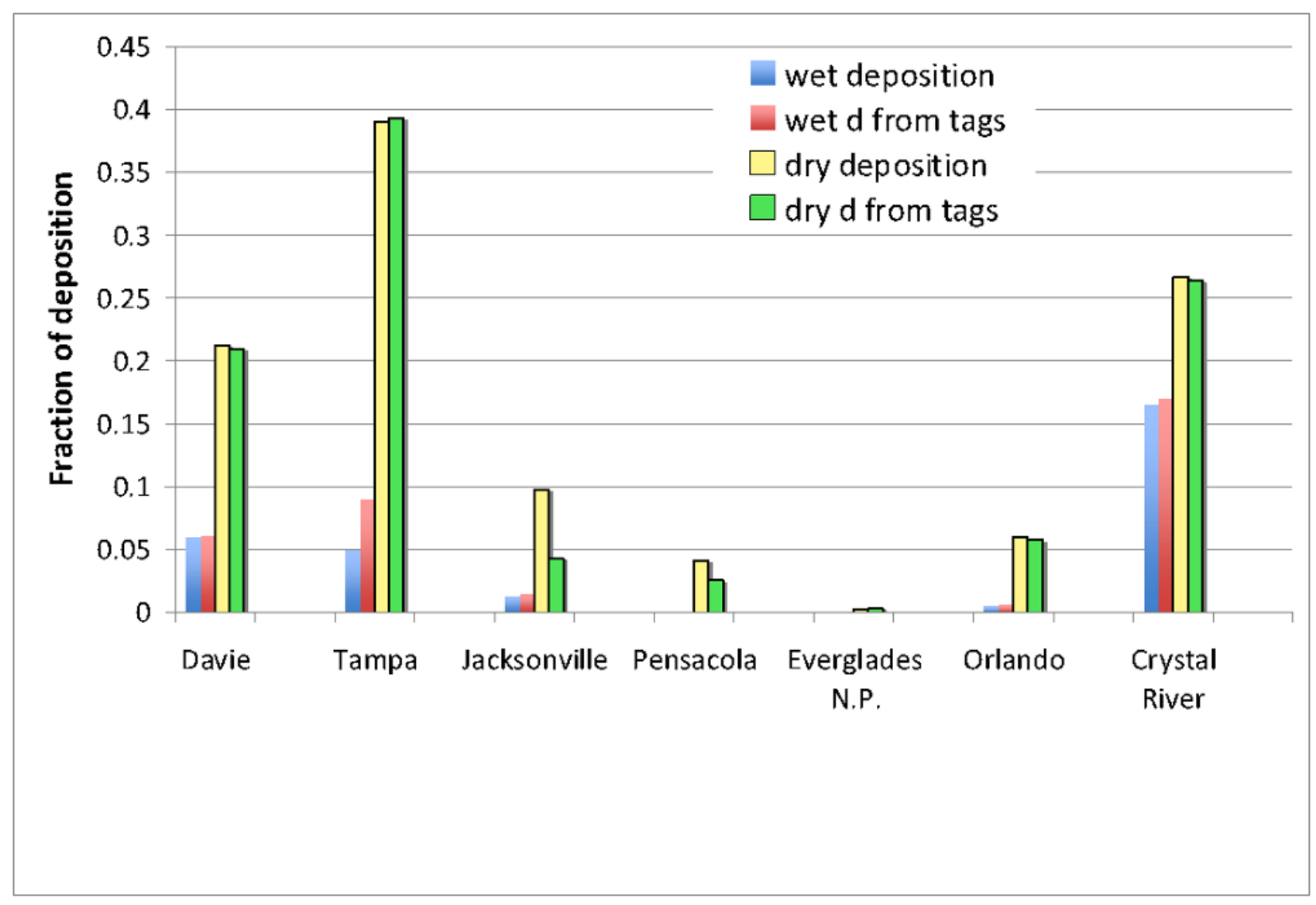

Fig. 1. Predicted reduction in wet and dry deposition of mercury as a fraction of total wet or dry deposition at seven sites in Florida from the CMAQ model in a scenario with a 50\% reduction in mercury emissions from all sources in the state of Florida. Predictions represent the difference between a model base case and an emission reduction scenario. These are compared with the reduction estimate derived from tagged emission sources.

Everglades National Park, and less than 3\% for wet deposition and $10 \%$ for dry deposition near the cities of Orlando and Pensacola).

Figure 1 also shows an evaluation of the tagging methodology. Predicted reductions in deposition found by comparing a model base case to a model scenario with reduced emissions are compared with the reductions inferred from source tags. Results are similar. The model mercury wet and dry deposition were also found to respond linearly to changes in emission rates for mercury in Florida.

Model wet deposition compares well with measured wet deposition at sites around the state (Figure 2). Annual wet deposition is biased high relative to measurements $(+35 \%)$, but this is due in part to frequent very light rain events (with less than $1 \mathrm{~mm}$ precipitation) in the model during winter months. These events may represent lightly precipitating fog and may not be included in the measurements of wet deposition. During the summer rainy season model wet deposition is biased high by just $7 \%$. Most notably, the model and measurements both show the highest wet deposition (both in absolute terms and in terms of deposition-to-precipitation ratios) at Davie and Everglades National Park sites in southern Florida, even though the model shows near-zero influence from local emissions at Everglades. Site-to-site variations in model wet deposition are broadly consistent with measurements.

However, the model ambient concentrations of mercury differ significantly from measured values. Model elemental mercury $\left(1.4-1.6 \mathrm{ng} / \mathrm{m}^{3}\right)$ is slightly higher than measured values $\left(1.2-1.4 \mathrm{mg} / \mathrm{m}^{3}\right)$ but falls within $20 \%$ of measured values. By contrast, model reactive gaseous mercury (RGM, $70 \mathrm{pg} / \mathrm{m}^{3}$ at Davie) exceeds the average measured value $\left(6 \mathrm{pg} / \mathrm{m}^{3}\right)$ by more than an order of magnitude. Model particulate mercury (34 $\mathrm{pg} / \mathrm{m}^{3}$ at Davie) also greatly exceeds measured values $\left(2 \mathrm{pg} / \mathrm{m}^{3}\right)$. The measured reactive and particulate mercury also show a strong diurnal cycle with nighttime values lower than daytime values by a factor of 10 . No such diurnal variation appears in the model. Previous modeling with CMAQ and REMSAD have shown ambient RGM from 30 to $60 \mathrm{pg} / \mathrm{m}^{3}$, somewhat lower than found here but still much higher than measurements. Previous aircraft measurements have found much higher 


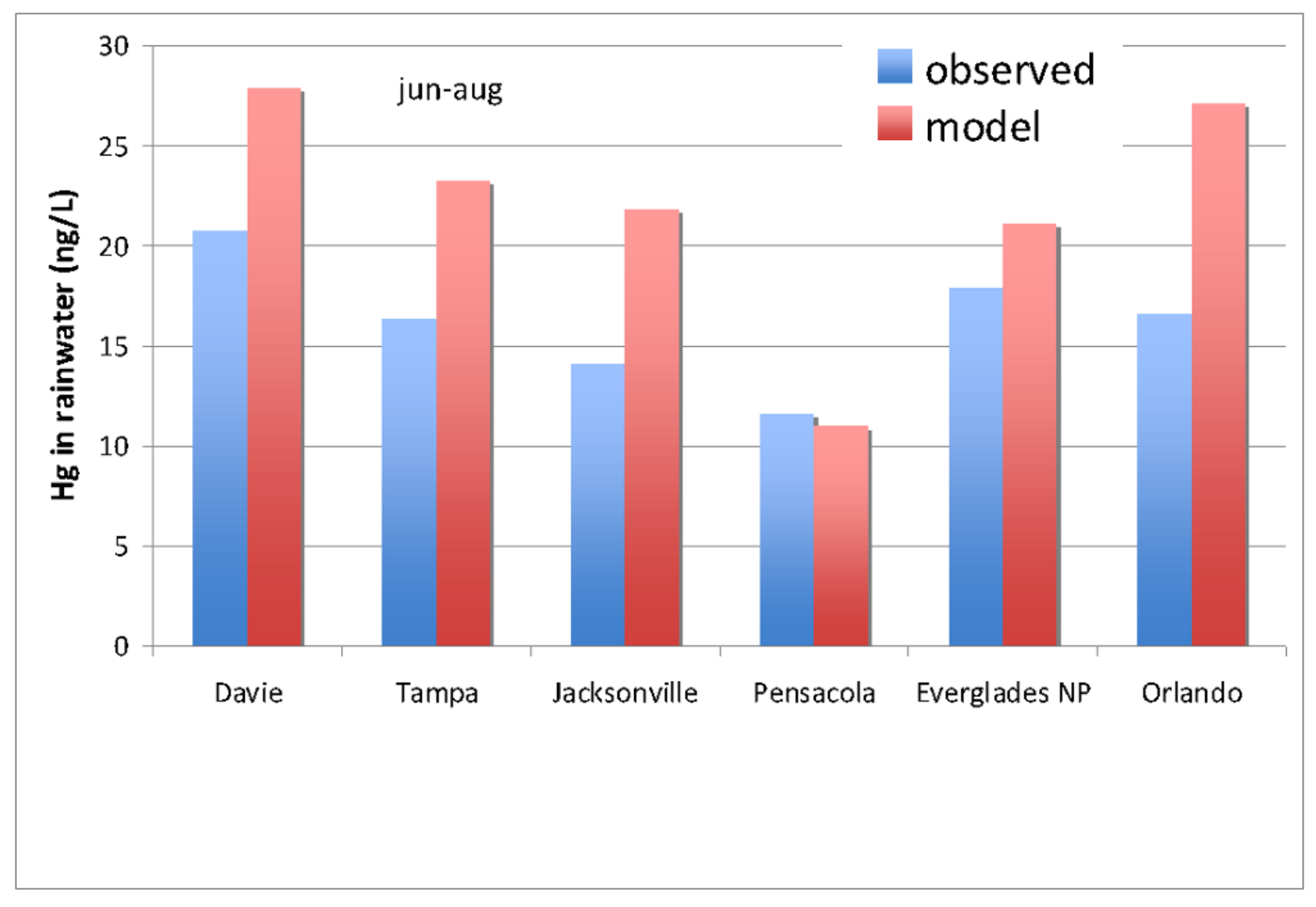

Fig. 2. Ratio of model wet deposition of mercury to model precipitation (ng/l) at six sites in Florida for June through August, 2009, compared to measured values.

ambient RGM (100 pg/m $\mathrm{m}^{3}$ at $2000-4000 \mathrm{~m}$.) which is in agreement with both regional and global models (Sillman et al., 2007, Selin and Jacob, 2008). Selin and Jacob also reported that the GEOS_chem global model overestimated ambient RGM in the southwestern US (100 pg/m $/ \mathrm{m}^{3}$ versus $6 \mathrm{pg} / \mathrm{m}^{3}$ measured).

Possible explanations for overestimated RGM in the model include the following: (i) rapid uptake of RGM by sea salt aerosols (Selin and Jacob, 2008) or other aqueous aerosols, which may be followed by deposition; (ii) reduction of RGM to elemental mercury by sulfate aerosols (Seigneur et al., 2006); or (iii) overestimated emission of RGM.

Although model RGM is consistently overestimated, site to site variations are broadly consistent between models and measurements. Model and measured values are both approximately 3 times higher at Davie than at Jacksonville, possibly reflecting the greater impact of local sources at Davie.

The model overestimate for RGM and possible explanations all have implications for the predicted impact of local emissions on deposition. The overestimate suggests that dry deposition of RGM (which is attributed largely to local emissions) may be overestimated. If the overestimate is due to either conversion from RGM to elemental mercury or overestimated emissions, this also suggests an overestimate of the role of local emissions. Alternatively, if RGM is rapidly absorbed by sea salt aerosols and deposited, then the model dry deposition may be correct despite the overestimated RGM. However, the possibility of rapid dry deposition suggests that transport from emission source regions to rural areas may be limited.

Evaluation of the accuracy of model predictions for local influences may be extended by examining correlations between mercury and other species. The model predicts that mercury concentrations in rainwater show no clear correlation with other deposited species. Model mercury concentration in rainwater shows little variation between Davie, Jacksonville and Pensacola while model values for nickel and lead are much higher at Davie due to the impact of local emissions. By contrast, model ambient RGM correlates with $\mathrm{NO}_{\mathrm{x}}$ and $\mathrm{SO}_{2}$, reflecting the impact of local sources. These predictions will be tested in comparison with measurements in the future.

\section{Conclusion}

The dominant role of global processes on mercury wet 
deposition in Florida may have implications for other ecosystems. Elevated wet deposition associated with global cycling of mercury is likely to be replicated in other tropical environments with heavy convective precipitation, including the West Indies and southeast Asia, with possible impacts on local food-producing ecosystems.

\section{Acknowledgements}

Funding for this project was provided by the State of Florida Department of Environmental Protection. We thank Nicola Pirrone, Ian Hedgecock, Teresa Lo Fuedo, Gerlinde Jung, and Gregor Schurmann at the CNR Institute of Atmospheric Pollution Research, CNR-IIA for completion of ECHMERIT global modeling. This work is in memory of Professor Jerry Keeler, who contributed immensely to the design of this study, but passed away prior to its completion.

\section{References}

Bullock, O. R., Jr., et al. (2008), The North American Mercury Model Intercomparison Study (NAMMIS):
Study description and model-to-model comparisons, J. Geophys. Res., 113, D17310, doi:10.1029/2008JD009803.

Seigneur, C., K. Vijayaraghavan, and K. Lohman (2006), Atmospheric mercury chemistry: sensitivity of global model simulations to chemical reactions, $J$. Geophys. Res., 111, D22306, doi:10.1029/2005JD006780.

Selin, N. E. and D. J. Jacob, Seasonal and spatial patterns of mercury wet deposition in the United States: Constraints on the contribution from North American anthropogenic sources, Atmospheric Environment 42, 5193-5204, 2008.

Selin, N. E., D. J. Jacob, R. J. Park, R. M. Yantosca, S. Strode, L. Jaegle', and D. Jaffe (2007), Chemical cycling and deposition of atmospheric mercury: Global constraints from observations, J. Geophys. Res., 112, D02308, doi:10.1029/2006JD007450.

Sillman, S., F. J. Marsik, K. I. Al-Wali, G J. Keeler, and M. S. Landis (2007), Reactive mercury in the troposphere: Model formation and results for Florida, the northeastern United States, and the Atlantic Ocean, J. Geophys. Res., 112, D23305, doi:10.1029/2006JD008227. 